\title{
Home-Based Physical Activity Programs for People With Dementia: Systematic Review and Meta-Analysis
}

\author{
Sara Isabel Lebre de Almeida, MSc, ${ }^{1,2,3,4}$ Madalena Gomes da Silva, PhD, ${ }^{5}$ and \\ Alda Sofia Pires de Dias Marques, PhD $^{1,2, *}$
}

'Lab 3R - Respiratory Research and Rehabilitation Laboratory, School of Health Sciences (ESSUA), ${ }^{2}$ nnstitute of Biomedicine (iBiMED), ${ }^{3}$ Department of Education and Psychology (DEP), University of Aveiro, and ${ }^{4}$ Instituto de Ciências Biomédicas Abel Salazar (ICBAS), University of Porto, 5 Interdisciplinary Centre of Health Applied Research, School of Health, Polytechnic Institute of Setúbal (ESS-IPS), Portugal.

\begin{abstract}
*Address correspondence to: Alda Sofia Pires de Dias Marques, PT, MSc, PhD, Lab 3R - Respiratory Research and Rehabilitation Laboratory, School of Health Sciences (ESSUA) and Institute for Biomedicine (iBiMED), University of Aveiro, Agras do Crasto - Campus Universitário de Santiago, Edifício 30, 3810-193 Aveiro, Portugal. E-mail: amarques@ua.pt
\end{abstract}

Received: July 16, 2019; Editorial Decision Date: November 14, 2019

Decision Editor: Patricia C. Heyn, PhD

\begin{abstract}
Background and Objectives: Physical activity has the potential to improve health outcomes in people with dementia, namely when living at home. However, the knowledge about home-based physical activity for this population is scarce. Thus, we aim to identify and synthesize the effects of home-based physical activity for people with dementia.

Research Design and Methods: A systematic review was conducted. Quality of studies was assessed using the Delphi List. Effect sizes (ES) were calculated with MetaXL 2.0. A meta-analysis was conducted for the Mini-Mental Status Examination (MMSE), Neuropsychiatric Inventory (NPI), Cornell Scale for Depression in Dementia, Alzheimer's Disease Cooperative Study Group Activities of Daily Living Scale (ADCS-ADL), Functional Reach test, Timed Up and Go (TUG) test, Short Physical Performance Battery, Dementia Quality of Life, NPI Caregivers subscale and Zarit Burden Interview (ZBI).

Results: Sixteen randomized controlled trials were included. Most were of high quality and published after 2015. A large heterogeneity of interventions was found. Meta-analysis showed significant results in MMSE (ES = 0.71, 95\% CI 0.43, $0.99)$, NPI (ES $=-0.37,95 \%$ CI $-0.57,-0.17$ ), ADCS-ADL (ES = 0.80, 95\% CI 0.53, 1.07), Functional Reach test $(\mathrm{ES}=2.24,95 \%$ CI 1.80, 2.68), TUG test $(\mathrm{ES}=-2.40,95 \%$ CI $-2.84,-1.96)$, NPI Caregivers subscale $(\mathrm{ES}=-0.63$, $95 \%$ CI $-0.94,-0.32)$, and ZBI (ES $=-0.45,95 \%$ CI $-0.77,-0.13)$. Few minor adverse events and high adherence to intervention were found.

Discussion and Implications: Home-based physical activity seems safe and effective in delaying cognitive function decline and improving changes in behavioral and psychological symptoms of dementia, activities of daily living, health-related physical fitness, and carer's burden in people with dementia living at home.
\end{abstract}

Keywords: Exercise, Nonpharmacological intervention, Major neurocognitive disorder

Dementia is a neurodegenerative syndrome that affects approximately 47.5 million people worldwide (Prince et al., 2015). This number is expected to grow to 131.5 million people by 2050 (Prince et al., 2015). Dementia is characterized by a decline in cognition and independence for activities of daily living (WHO, 2012), making it a major cause of incapacity and dependency among older people. Currently, most people with dementia live in their own homes (WHO, 2012), with about one third of them living alone (Ebly, Hogan, \& Rockwood, 1999). Therefore, 
the development of home-based interventions is vital to inform the provision of care for people with dementia (WHO, 2012).

A highly recommended nonpharmacological intervention to manage symptoms of dementia is physical activity (Forbes, Thiessen, Blake, Forbes, \& Forbes, 2015; Regier, Hodgson, \& Gitlin, 2016; Sallis et al., 2016). Physical activity is defined as "any body movement produced by skeletal muscles that requires energy expenditure" (Caspersen, Powell, \& Christenson, 1985).

Although studies looking at the effects of home-based physical activity programs exist, results are widespread in the literature. The published systematic reviews on physical activity in people with dementia found improvements in executive function, activities of daily living, falls prevention, cognitive decline, mobility, physical function, fitness, and positive behavior (Blankevoort et al., 2010; Burton et al., 2015; Forbes et al., 2015; Heyn, Abreu, \& Ottenbacher, 2004; Pitkälä, Savikko, Poysti, Strandberg, \& Laakkonen, 2013; Potter, Ellard, Rees, \& Thorogood, 2011; Rao, Chou, Bursley, Smulofsky, \& Jezequel, 2014). However, these reviews included studies conducted in different or undistinguishable settings, hindering comparisons across different settings and consequently, conclusions regarding the effects of physical activity at home (Blankevoort et al., 2010; Burton et al., 2015; Forbes et al., 2015; Heyn et al., 2004; Pitkälä, Savikko, et al., 2013; Potter et al., 2011; Rao et al., 2014). Looking at these effects separately is important to guide personalized interventions and future research in the setting where people with dementia spend more time. Thus, the aim of this systematic review was to identify and synthesize the effects of home-based physical activity in people with dementia.

\section{Methods}

Searches in the Cochrane Library and the International Prospective Register of Systematic Reviews (PROSPERO) were conducted prior to the development of the present systematic review to exclude the existence of reviews or protocols with the same purpose as this study.

The protocol for this systematic review was registered at International Prospective Register of Systematic Reviews (registration no. CRD42017059951) and is available on request. PRISMA checklist can be found in Supplementary Appendix 3.

\section{Search Strategy and Selection Criteria}

This systematic review followed the recommended Preferred Reporting Items for Systematic reviews and Meta-Analyses (PRISMA) guidelines (Moher, Liberati, Tetzlaff, Altman, \& The Prisma Group, 2009).

Literature searches were performed in the Cochrane, PubMed, SCOPUS, LILACS, Web of knowledge, and EBSCOhost databases. Additional searches were performed in weekly automatic updates retrieved from the databases until March 2019. Electronic search was supplemented by hand searching of references lists of the included studies and key articles on the topic. Search strategy can be found in Supplementary Appendix 1, Table 1.

Studies were considered eligible if they: (i) were randomized controlled trials; (ii) were written in Portuguese, English, French, or Spanish languages; (iii) involved physical activity in home-based settings for people with dementia; (iv) included participants diagnosed with dementia; and (v) had at least one measure that assessed the outcomes of the intervention. Studies were excluded if: (i) involved proxy versions, (ii) were non randomized controlled trials, observational studies, qualitative studies, news, research protocols, theses, dissertations, abstracts, letters to the editor, unpublished work, commentaries, book chapters, systematic reviews (references on the topic checked), guidelines (references on the topic checked), statements (references on the topic checked) and position papers (references on the topic checked), and (iii) were conducted in animals.

Articles were initially screened (title and abstracts) by the first author. The second author was consulted in case of uncertainty. A random sample of $10 \%$ of the abstracts was independently screened by the third author to guarantee consistency. Full texts of potentially relevant articles were screened independently by the first and third authors. Disagreements between the reviewers were solved by consensus.

\section{Quality Assessment and Data Extraction}

Two reviewers independently assessed the methodological quality of each study using the Delphi-List, which is composed by nine items rated as yes/no (Verhagen et al., 1998). The total score ranges from 0 to 9 points and consists of summing the number of items that are satisfied (e.g., evaluated as yes; Verhagen et al., 1998). The cutoff point defining high-quality studies was set at $\geq 5$ points (Verhagen et al., 1998). The Delphi-List has been used in a previous meta-analysis of the effects of exercise in people with dementia (Heyn et al., 2004).

Data from the included studies were extracted and synthesized in a structured table format that can be found in Supplementary Appendix 1, Table 3. Studies with multiple publications were identified to avoid duplicate reports (e.g., double counting of outcomes and/or number of participants). Corresponding authors of the included studies were contacted via e-mail to request additional data/information when required.

\section{Data Analysis and Synthesis}

Inter-rater agreement was assessed using Cohen's kappa coefficient to explore the consistency of the quality assessment performed by the two authors. The cutoff points of the Cohen's Kappa ranges from 0 to 1 : slight $(\leq 0.20)$, fair 
(0.21-0.40), moderate (0.41-0.60), and substantial ( $\geq 0.81)$ agreement (Landis \& Koch, 1977). Statistical analysis was performed using IBM SPSS version 24.0 (IBM, Armonk, New York).

Meta-analyses were conducted to evaluate the effects of home-based physical activity on different domains, whenever possible. All eligible studies were kept for meta-analysis independently of their quality score as relatively scarce research has been conducted in the field. For variables that did not fit the meta-analysis, effect size (ES) were calculated whenever possible, allowing the quantification of the effectiveness of the intervention. The ES were interpreted as small $(\geq 0.20)$, medium $(\geq 0.50)$, or large $(\geq 0.80)$; Cohen (1988). MetaXL 2.0 was used to calculate the individual and pooled ES. The input was the pooled Cohen's $d$ value and corresponding standard error; and the output was the pooled Cohen's $d$ value and corresponding confidence intervals $(\mathrm{CI})$.

\section{Results}

\section{Study Selection}

A PRISMA Flow Diagram can be found in Figure 1 (Moher et al., 2009), showing the screening process and reasons for exclusion of studies. The search generated 11,160 studies from which 16 studies were included in the final analysis (please see Supplementary Appendix 1, Table 7).

\section{Quality Assessment}

Thirteen studies were rated as high quality and three studies as low quality (see Supplementary Appendix 1,

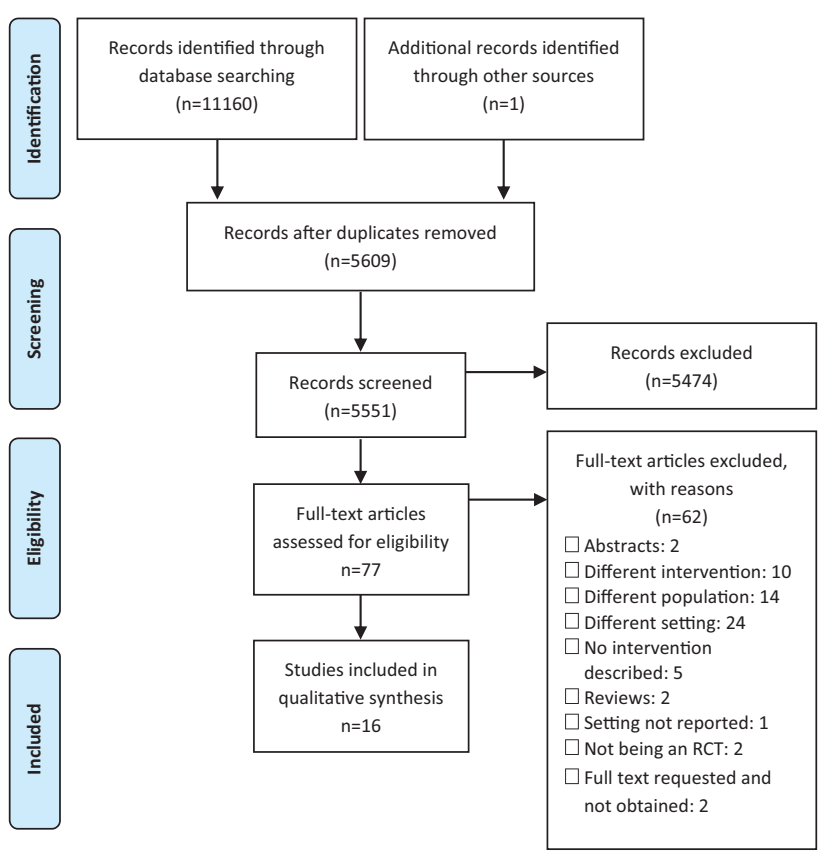

Figure 1. PRISMA flow chart diagram showing the articles screened and included in the study ( $\mathrm{n}=16 \mathrm{RCTs})$.
Table 2). Supplementary Appendix 1, Table 2, shows the quality assessment details from the Delphi-list. Interrater agreement regarding the quality assessment was substantial-Cohen's Kappa $=0.91(p<.001) ; 95 \%$ CI $[0.74,1.08]$.

\section{Study Characteristics}

Most studies were conducted in the United States of America (USA) and Australia (see Supplementary Appendix 1, Table 3). In Europe only northern countries (e.g., England (D’Amico et al., 2016; Lowery et al., 2014), Germany (Holthoff et al., 2015), Finland (Öhman et al., 2016, 2017; Pitkälä, Pöysti, et al., 2013), and Netherlands (Prick, de Lange, Scherder, Twisk, \& Pot, 2017) reported home-based physical activity for people with dementia.

A total of 1,129 participants with 500 in home-based experimental groups, 137 in other experimental groups (e.g., group exercise, light exposure) and 492 in control groups participated in the reported studies, with sample sizes ranging from 22 (Wesson et al., 2013) to 210 (Öhman et al., 2016, 2017; Pitkälä, Pöysti, et al., 2013) participants. Participants had a mean age of $77.3 \pm 7.3[51,99]$ years old, $51.1 \%(n=810)$ were male and presented a Mini-Mental Status Examination (MMSE) mean score of $19.9 \pm 5.9$ $[15.3,25.6]$ points. There were only five studies reporting on the type and severity of dementia (D'Amico et al., 2016; Pitkälä, Pöysti et al., 2013; Suttanon et al., 2013; Teri et al., 2003; Vreugdenhil, Cannell, Davies, \& Razay, 2012) and results were never differentiated according to these variables. Eight of the 16 studies investigated the mediumand long-term (3, 4, 6, 12, 18 and 24 months) effects of the home-based physical activity (see Supplementary Appendix 1, Table 3). Supplementary Appendix 1, Tables 3 and 4, and Supplementary Appendix 2, Table 1, present details of the included studies.

\section{Design of the Programs}

Interventions lasted from 2 months (McCurry et al., 2011) to 2 years (Callahan et al., 2017), being 12 weeks (Supplementary Appendix 1, Table 3) the most common duration. Frequencies of the intervention ranged from daily (D’Amico et al., 2016; Lowery et al., 2014; Steinberg, M., Podewils, \& Lyketsos, 2009) to 4-6 times per 2 months (Suttanon et al., 2013) and the length of the sessions ranged from 20 to $30 \mathrm{~min}$ (please see Supplementary Appendix 2, Table 1) to $12 \mathrm{hr}$ (Teri et al., 2003). All interventions included home visits, with exception of one study (i.e., phone contacts; Vreugdenhil et al., 2012). Interventions included a wide variety of combinations across cardiorespiratory endurance, muscle strength and endurance, flexibility and neuromotor components (please see Supplementary Appendix 1, Tables 3 and 4). The most common included activity was walking (Supplementary Appendix 2, Table 1). Some studies also added to the physical activity 
intervention, cognitive training, goal setting, home modification, booklets or brochures, education to improve adherence, psychoeducation, communication training, problem solving, pleasant/meaningful activities, and carer education. Phone calls and dyad involvement were also reported. More details are presented in Supplementary Appendix 1, Table 3.

\section{Outcomes and Outcome Measures}

A total of nine outcome domains, measured by 75 different measurement tools were identified. Each study reported an average of 3.9 [1-8] different outcome domains and 6.4 [2-15] different measurement tools. Reported outcome domains were cognitive function $(n=8)$, changes in behavioral and psychological symptoms of dementia $(n=10)$, activities of daily living $(n=6)$, health-related physical fitness $(n=10)$, physical activity $(n=3)$, falls $(n=2)$, health-related quality of life $(n=5)$, carer's burden $(n=6)$, and costs $(n=1)$; see Supplementary Appendix 1, Tables 3 and 5. Most frequently reported outcome measures in the included studies were Neuropsychiatric Inventory (NPI) $(n=6)$, MMSE $(n=5)$, Cornell Scale for Depression in Dementia $(n=5)$, Zarit Burden Interview (ZBI) $(n=4)$, Five Times Sit to Stand test $(n=2)$, Alzheimer's Disease Cooperative Study Group Activities of Daily Living Scale-ADCSADL $(n=2)$, Falls Efficacy Scale $(n=2)$, Functional Reach test $(n=2)$, General Health Questionnaire $(n=2)$, NPI caregiver $(n=2)$, Lawton $\&$ Brody scale $(n=2)$, Short Physical Performance Battery $(n=2), 8$-foot walk test $(n=2)$, and TUG test $(n=2)$; see , Supplementary Appendix 1, Tables 3 and 5.

\section{Effectiveness of the Home-Physical Activity}

Table 1 synthesizes the ES found per domain. For more detail, please see Supplementary Appendix 2 (Details of the ES per domain).

Neuropsychiatric Inventory Caregivers sub-scale: The overall pooled ES for the (i) MMSE was medium and positive (ES = 0.71, 95\% CI 0.43, 0.99); (ii) NPI was small and negative (ES $=-0.37,95 \% \mathrm{CI}-0.57,-017$ ); (iii) the overall pooled ES for the ADCS-ADL was large and positive $(\mathrm{ES}=0.80,95 \%$ CI 0.53, 1.07); (iv) Functional Reach test was large and positive ( $\mathrm{ES}=2.24,95 \% \mathrm{CI} 1.80,2.68$ ); and $(\mathrm{v})$ TUG test was large and negative (ES $=-2.40,95 \%$ CI $-2.84,-1.96)$; Figure 2. No significant differences were found for Cornell Scale for Depression in Dementia, Short Physical Performance Battery and Dementia Quality of Life.

Carer's burden effectiveness was analyzed with the NPI Caregivers subscale and the ZBI. Overall pooled ES was medium and negative $(E S=-0.63,95 \%$ CI $-0.94,-0.32$ ) for NPI Caregivers subscale and low and negative $(E S=-0.45$, $95 \%$ CI $-0.77,-0.13$ ) for ZBI (Figure 3).

\section{Adverse Events}

A total of 10 studies (Dawson, Judge, \& Gerhart, 2017; Lowery et al., 2014; McCurry et al., 2011; Padala et al., 2017; Pitkälä, Pöysti, et al., 2013; Prick et al., 2017; Steinberg et al., 2009; Suttanon et al., 2013; Teri et al., 2003; Wesson et al., 2013) explored the adverse events of home-based physical activity programs. Only three studies (Dawson et al., 2017; Steinberg et al., 2009; Wesson et al., 2013) found minor adverse events related or possibly related with intervention. More information about the adverse events can be found in Supplementary Appendix 1, Table 6.

\section{Dropouts and Adherence}

Five studies (McCurry et al., 2011; Padala et al., 2017; Prick et al., 2017; Suttanon et al., 2013; Teri et al., 2003) reported dropouts, ranging between $8 \%$ (Teri et al., 2003) and $27.5 \%$ (Suttanon et al., 2013). Reasons reported to dropout were: carers were not able to dedicate the necessary time (Padala et al., 2017), carer found the effort excessive (Suttanon et al., 2013), the carer preferred the participant to be in an exercise group (Suttanon et al., 2013), loss of interest (Padala et al., 2017), health problems (Prick et al., 2017; Suttanon et al., 2013), burden (Prick et al., 2017), institutionalization (Prick et al., 2017; Suttanon et al., 2013; Teri et al., 2003), hospitalization (Prick et al., 2017; Suttanon et al., 2013), and death (Prick et al., 2017; Suttanon et al., 2013).

Eleven studies reported adherence to the intervention (Dawson et al., 2017; Holthoff et al., 2015; Lowery et al., 2014; McCurry et al., 2011; Öhman et al., 2016; Padala et al., 2017; Pitkälä, Pöysti, et al., 2013; Steinberg et al., 2009; Suttanon et al., 2013; Teri et al., 2003; Wesson et al., 2013). Adherence varied between poor (Lowery et al., 2014) and excellent (Dawson et al., 2017; Holthoff et al., 2015; Padala et al., 2017), with six studies reporting good to very high adherence (Öhman et al., 2016; Pitkälä, Pöysti, et al., 2013; Steinberg et al., 2009; Suttanon et al., 2013; Teri et al., 2003; Wesson et al., 2013). This variance across adherence levels could be expected as interventions were heterogeneous and the existing evidence regarding effective adherence strategies is limited (van der Wardt et al., 2017).

\section{Discussion}

This systematic review provided a synthesis of the effects of home-based physical activity in people with dementia. Most studies were of high quality and published after 2015 (first article published in 2003), indicating that this is a relatively new topic of research. High heterogeneity of the designs of home-based physical activity interventions was found. Overall, medium to large delay of cognitive function decline and improvements in changes in behavioral and psychological symptoms of dementia, activities 
Table 1. Synthesis of the Effect Sizes per Domain.

\begin{tabular}{|c|c|c|c|c|c|c|}
\hline \multirow[b]{3}{*}{ Domains } & \multicolumn{6}{|l|}{ Effect sizes (Cohen's $d$ ) } \\
\hline & \multicolumn{2}{|l|}{ Small $(\geq 0.20)$} & \multicolumn{2}{|l|}{ Medium $(\geq 0.50)$} & \multicolumn{2}{|l|}{ Large $(\geq 0.80)$} \\
\hline & Negative & Positive & Negative & Positive & Negative & Positive \\
\hline $\begin{array}{l}\text { Cognitive } \\
\text { function }\end{array}$ & $\begin{array}{l}{[-0.35 \text { to }-0.2] \text { (Prick et al., }} \\
2017)\end{array}$ & $\begin{array}{l}{[0.41 \text { to } 0.49]} \\
\text { (Öhman et al., } \\
\text { 2016; Vreugdenhil } \\
\text { et al., 2012) }\end{array}$ & $\begin{array}{l}{[-0.58]} \\
\text { (Vreugdenhil } \\
\text { et al., 2012) }\end{array}$ & $\begin{array}{l}{[0.56] \text { (Dawson }} \\
\text { et al., 2017) }\end{array}$ & $\begin{array}{l}{[-4.93] \text { (Holthoff }} \\
\text { et al., 2015) }\end{array}$ & $\begin{array}{l}{[1.11 \text { to } 4.75]} \\
\text { (Holthoff et al., } \\
\text { 2015; Padala } \\
\text { et al., 2017) }\end{array}$ \\
\hline $\begin{array}{l}\text { Changes in } \\
\text { BPSD }\end{array}$ & $\begin{array}{l}\text { [-0.49 to }-0.2] \text { (Callahan } \\
\text { et al., 2017; D’Amico } \\
\text { et al., 2016; Öhman et al., } \\
\text { 2017; Teri et al., 2003; } \\
\text { Vreugdenhil et al., 2012) }\end{array}$ & - & $\begin{array}{l}{[-0.42]} \\
\text { (McCurry et al., } \\
\text { 2011) }\end{array}$ & $\begin{array}{l}\text { [0.6 to } 0.62] \\
\text { (McCurry et al., } \\
\text { 2011; Öhman } \\
\text { et al., 2017) }\end{array}$ & $\begin{array}{l}{[-8.72 \text { to }-1.08]} \\
\text { (Holthoff et al., } \\
\text { 2015; McCurry } \\
\text { et al., 2011; } \\
\text { Öhman et al., } \\
\text { 2017) }\end{array}$ & $\begin{array}{l}\text { [0.8 to } 2.18] \\
\text { (McCurry et al., } \\
\text { 2011; Öhman } \\
\text { et al., 2017) }\end{array}$ \\
\hline ADLs & $\begin{array}{l}{[-0.32] \text { (Dawson et al., }} \\
2017)\end{array}$ & $\begin{array}{l}{[0.33]} \\
\text { (Vreugdenhil } \\
\text { et al., 2012) }\end{array}$ & - & $\begin{array}{l}\text { [0.62] } \\
\text { (Vreugdenhil } \\
\text { et al., 2012) }\end{array}$ & $\begin{array}{l}{[-1.08] \text { (Padala }} \\
\text { et al., 2017) }\end{array}$ & $\begin{array}{l}{[1.47 \text { to } 5.27]} \\
\text { (Holthoff et al., } \\
2015 ; \text { Padala } \\
\text { et al., 2017) }\end{array}$ \\
\hline $\begin{array}{l}\text { Health-related } \\
\text { physical fit- } \\
\text { ness }\end{array}$ & $\begin{array}{l}{[-0.43 \text { to }-0.34] \text { (Suttanon }} \\
\text { et al., 2013; Wesson et al., } \\
2013)\end{array}$ & $\begin{array}{l}\text { [0.28 to } 0.48] \\
\text { (Dawson et al., } \\
\text { 2017; Pitkälä, } \\
\text { Pöysti, et al., } \\
\text { 2013; Suttanon } \\
\text { et al., 2013) }\end{array}$ & $\begin{array}{l}{[-0.68 \text { to }-0.51]} \\
\text { (Suttanon } \\
\text { et al., 2013; } \\
\text { Vreugdenhil } \\
\text { et al., 2012; } \\
\text { Wesson et al., } \\
\text { 2013) }\end{array}$ & $\begin{array}{l}{[0.65 \text { to } 0.75]} \\
\text { (Dawson et al., } \\
\text { 2017; Teri } \\
\text { et al., 2003; } \\
\text { Vreugdenhil } \\
\text { et al., 2012) }\end{array}$ & $\begin{array}{l}{[-2.2 \text { to }-0.86]} \\
\text { (Padala et al., } \\
\text { 2017; Suttanon } \\
\text { et al., 2013) }\end{array}$ & $\begin{array}{l}\text { [0.98 to 7] } \\
\text { (Dawson et al., } \\
\text { 2017; Padala } \\
\text { et al., 2017; } \\
\text { Suttanon } \\
\text { et al., 2013; } \\
\text { Vreugdenhil } \\
\text { et al., 2012) }\end{array}$ \\
\hline $\begin{array}{l}\text { Physical } \\
\text { activity }\end{array}$ & {$[-0.35]^{47}$} & - & - & - & - & $\begin{array}{l}0.83 \text { (Wesson } \\
\text { et al., 2013) }\end{array}$ \\
\hline Falls & $\begin{array}{l}{[-0.28 \text { to }-0.2] \text { (Suttanon }} \\
\text { et al., 2013; Wesson et al., } \\
2013 \text { ) }\end{array}$ & - & $\begin{array}{l}{[-0.59 \text { to }-0.56]} \\
\text { (Suttanon et al., } \\
2013 \text { ) }\end{array}$ & - & - & - \\
\hline HRQoL & $\begin{array}{l}{[-0.23] \text { (Suttanon et al., }} \\
\text { 2013) }\end{array}$ & $\begin{array}{l}{[0.36] \text { (Lowery }} \\
\text { et al., 2014) }\end{array}$ & - & - & - & $\begin{array}{l}\text { [1.91] (Padala } \\
\text { et al., 2017) }\end{array}$ \\
\hline $\begin{array}{l}\text { Carer's } \\
\text { burden }\end{array}$ & $\begin{array}{l}{[-0.26] \text { (D'Amico et al., }} \\
2016)\end{array}$ & - & $\begin{array}{l}{[-0.52]} \\
\text { (Vreugdenhil } \\
\text { et al., 2012) }\end{array}$ & - & $\begin{array}{l}{[-3.9] \text { (Holthoff }} \\
\text { et al., 2015) }\end{array}$ & - \\
\hline Costs & $\begin{array}{l}{[-0.21 \text { to }-0.43] \text { (D'Amico }} \\
\text { et al., 2016) }\end{array}$ & $\begin{array}{l}{[0.22 \text { to } 0.23]} \\
\text { (D'Amico et al., } \\
2016)\end{array}$ & - & - & - & - \\
\hline
\end{tabular}

Note: ADLs = activities of daily living; BPSD = behavioral and psychological symptoms of dementia; HRQoL = health-related quality of life.

of daily living, health-related physical fitness, physical activity, falls, health-related quality of life, and carer's burden were observed. Despite heterogeneous use of measurement tools, it was possible to conduct a meta-analysis for some outcome measures. Home-based physical activity in people with dementia seems to be effective on delaying cognitive function decline, assessed with MMSE (Holthoff et al., 2015; Öhman et al., 2017; Vreugdenhil et al., 2012), improving changes in behavioral and psychological symptoms of dementia with NPI (Callahan et al., 2017; D'Amico et al., 2016; Holthoff et al., 2015; Öhman et al., 2017), activities of daily living with ADCS-ADL (Callahan et al., 2017; Holthoff et al., 2015), health-related physical fitness with Functional Reach test (Suttanon et al., 2013; Vreugdenhil et al., 2012) and TUG test (Suttanon et al., 2013; Vreugdenhil et al., 2012) and carer's burden with NPI Caregivers subscale (Holthoff et al., 2015; Lowery et al., 2014), and ZBI (D'Amico et al., 2016; Suttanon et al., 2013; Vreugdenhil et al., 2012; Wesson et al., 2013). Moreover, home-based physical activity interventions seem to be safe and present high adherence.

The observed high heterogeneity in the designs, outcomes, and outcome measures leads to difficulties in determining which structure is more effective for home-based physical activity interventions in people with dementia. Nevertheless, some similarities were identified across 


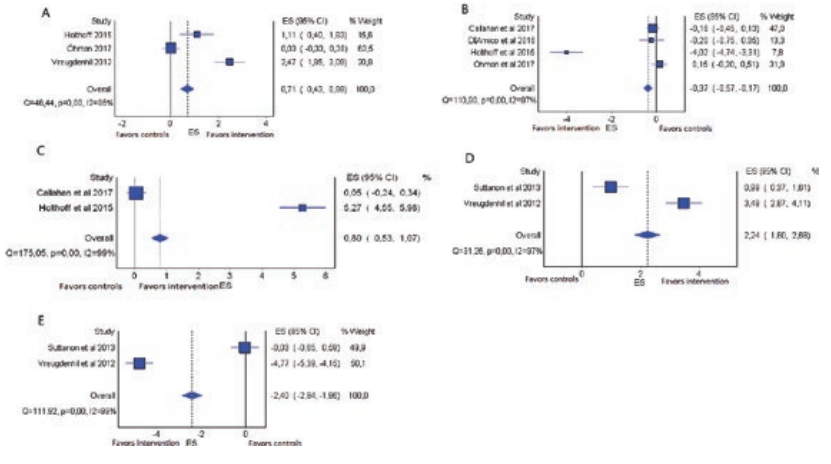

Figure 2. Forest plot of the home-based physical activity programs on (A) the Mini-Mental Status Examination, (B) Neuropsychiatric Inventory, (C) Alzheimer's Disease Cooperative Study Group Activities of Daily Living scale, (D) Functional Reach test, and (E)Timed Up and Go test in people with dementia.
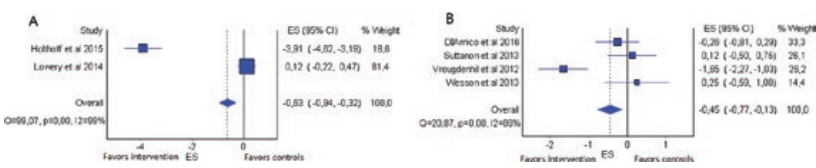

Figure 3. Forest plot of home-based physical activity programs on carer's burden measured with (A) the Neuropsychiatric Inventory Caregivers subscale and with (B) the Zarit Burden Interview in people with dementia.

studies, that is, an intervention duration of 12 weeks was commonly (4/13) reported and walking was the physical activity most widely used. Walking is a simple intervention, easily implemented on a home environment, previously recommended to stabilize cognitive function (Venturelli, Scarsini, \& Schena, 2011), physical performance, and activities of daily living (Venturelli et al., 2011; Vreugdenhil et al., 2012) in people with Alzheimer's disease. However, it should be acknowledged that walking is just a possible option and more research is still needed on the efficacy and adherence across home-based physical activity programs for people with dementia.

A substantial heterogeneity was found in the reported outcomes and outcome measures. Nevertheless, some outcomes and outcome measures, which have been used in physical activity interventions for people with dementia (Gonçalves, Cruz, Marques, Demain, \& Samuel, 2018; Gonçalves, Samuel, Ramsay, Demain, \& Marques, 2019), were reported more than once, making it possible to perform meta-analysis for a home-based setting. Although, high heterogeneity and some similarities across studies have been previously reported in other systematic reviews looking at the effects of physical activity on health-related physical fitness (Blankevoort et al., 2010; Lam et al., 2018), activities of daily living (Blankevoort et al., 2010), or functionality (Pitkälä, Savikko, et al., 2013), none have examined the overall effects of home-based physical activity in people with dementia.

Home-based physical activity interventions seem to be effective for people with dementia, that is, delaying cognitive function decline and improving changes in behavioral and psychological symptoms, activities of daily living and health-related physical fitness but also for carers, decreasing their burden. Positive effects on cognitive function and changes in behavioral and psychological symptoms of dementia are controversial in some literature reviews (Barreto, Demougeot, Pillard, Lapeyre-Mestre, \& Rolland, 2015; Forbes et al., 2015; Heyn et al., 2004; Potter et al., 2011; Rao et al., 2014). It is possible that this systematic review was able to find positive results because it only included home-based interventions and pooled data from measurement tools consistently used on physical activity programs in people with dementia (i.e., MMSE and NPI; Gonçalves et al., 2018). Previous literature have also showed improvements on activities of daily living (BorgesMachado et al., 2019; Forbes et al., 2015; Lewis, Peiris, \& Shields, 2017; Rao et al., 2014), health-related physical fitness(Heyn et al., 2004; Potter et al., 2011; Rao et al., 2014), and carer's burden(Zeng et al., 2016) after physical activity for people with dementia in different settings, which are key factors to maintain their independence (Physical Activity Guidelines Advisory Committee, 2018). This systematic review corroborates these findings indicating that, keeping people with dementia active at home may allow them to stay well at home, which is in line with international policy for dementia care (Burns, 2000; Moïse, Schwarzinger, Um, \& Dementia Experts' Group, 2004; WHO, 2012).

Although levels of physical activity (Suttanon et al., 2013; Teri et al., 2003; Wesson et al., 2013), falls (Suttanon et al., 2013; Wesson et al., 2013), health-related quality of life (D'Amico et al., 2016; Lowery et al., 2014; Padala et al., 2017; Steinberg et al., 2009; Suttanon et al., 2013), and costs (D'Amico et al., 2016), are also important outcomes for the wide dissemination of home-based physical activity intervention, a limited number of studies reported on them or used different measures, which impairs comparison of the results. There is a need to identify a minimum set of measures that can contribute to clarify the controversy in the literature and guide future research to enhance our knowledge on the costs as well as the effects of home-based physical activity in people with dementia (Gonçalves et al., 2018; Van Ooteghem et al., 2018).

Overall this systematic review found mostly good to excellent adherence to home-based physical activity (Dawson et al., 2017; Holthoff et al., 2015; Öhman et al., 2016; Padala et al., 2017; Pitkälä, Pöysti, et al., 2013; Steinberg et al., 2009; Suttanon et al., 2013; Teri et al., 2003; Wesson et al., 2013). Adherence has been found to vary across different studies (van der Wardt et al., 2017) and although good levels have been previously reported (Burton et al., 2015; Rao et al., 2014), it has been acknowledged that physical activity at home and individualized interventions seems to be key factors to improve adherence in people with dementia (Suttanon, Hill, Said, Byrne, \& Dodd, 2012; van der Wardt et al., 2017). 
Individual, biological but also social environmental factors are determinants to physical activity behavior (Bauman et al., 2012). Thus, motivation/willingness of people with dementia to participate in physical activity interventions may be influenced by their individual characteristics, countries (in this review studies were implemented in six different countries), and cultures. Furthermore, very few and minor adverse events were reported, indicating that home-based physical activity is a safe approach. Future research should consider exploring the impact of important variables such as the type and severity of dementia on the results obtained and study the long-term effects of such programs.

\section{Limitations}

This systematic review has several limitations that need to be acknowledged. Firstly, there is a possibility of having missed some studies because articles published in other languages than English, Spanish, French, and/or Portuguese were not included. Thorough searches were however conducted in different databases to minimize as much as possible this limitation. Secondly, because the search only included randomized controlled trials, data of other peerreviewed work, unpublished work, or gray literature were not included. Nevertheless, this is the best design to reduce bias when studying interventions. Finally, although most of the included studies were of high quality, which has minimized some limitations, the large diversity of designs, outcomes, outcome measures and control groups found, hampered the synthesis of results. Due to this difficulty and the relatively scarce research in the field of home-based physical activity interventions for people with dementia, we decided to include one poor-quality study in the metaanalysis. However, this may have affected its quality. Therefore, more research with robust methodologies is recommended so an update of this systematic review and meta-analysis can be conducted in the future and guide strong recommendations of home-based physical activity in people with dementia.

\section{Conclusion}

This systematic review identified the designs and synthesized the effects of home-based physical activity in people with dementia. This intervention seems to be effective to delay cognitive function decline and improve changes in behavioral and psychological symptoms of dementia, activities of daily living, health-related physical fitness and carer's burden in people with dementia living at home. Overall home-based physical activity interventions seem to be safe and present high adherence. This is important for professionals to be confident to encourage physical activity at home in people with dementia. However, there is a need to establish recommendations with the most effective intervention structure and components as well as the minimum set of outcomes and outcome measures to assess home-base physical activity in people with dementia.

\section{Supplementary Material}

Supplementary data are available at The Gerontologist online.

\section{Funding}

This work was funded by Fundação para a Ciência e a Tecnologia (FCT) [ref. SFRH/BD/120695/2016] and partially funded by Programa Operacional de Competitividade e Internacionalização - POCI, through Fundo Europeu de Desenvolvimento Regional FEDER (POCI-01-0145-FEDER-007628) and by national funds (OE), through FCT, I.P., under the project UID/BIM/04501/2013 and UID/BIM/04501/2019 in the scope of the framework contract foreseen in the numbers 4,5 , and 6 of the article 23, of the DecreeLaw 57/2016, of August 29, changed by Law 57/2017, of July 19.

\section{Acknowledgments}

The authors would like to acknowledge all authors who send us their data that enriched this systematic review. A special thanks to Vera Afreixo for her assistance on the data analysis.

\section{Conflict of Interest}

None declared.

\section{References}

Barreto, P. S., Demougeot, L., Pillard, F., Lapeyre-Mestre, M., \& Rolland, Y. (2015). Exercise training for managing behavioral and psychological symptoms in people with dementia: A systematic review and meta-analysis. Ageing Research Reviews, 24, 274-285. doi:10.1016/j.arr.2015.09.001

Bauman, A. E., Reis, R. S., Sallis, J. F., Wells, J. C., Loos, R. J., \& Martin, B. W., Lancet Physical Activity Series Working Group. (2012). Correlates of physical activity: Why are some people physically active and others not? Lancet (London, England), 380, 258-271. doi:10.1016/S0140-6736(12)60735-1

Blankevoort, C. G., van Heuvelen, M. J., Boersma, F., Luning, H., de Jong, J., \& Scherder, E. J. (2010). Review of effects of physical activity on strength, balance, mobility and ADL performance in elderly subjects with dementia. Dementia and Geriatric Cognitive Disorders, 30, 392-402. doi:10.1159/000321357

Borges-Machado, F., Ribeiro, Ó., Sampaio, A., Marques-Aleixo, I., Meireles, J., \& Carvalho, J. (2019). Feasibility and impact of a multicomponent exercise intervention in patients with Alzheimer's disease: A pilot study. American Journal of Alzheimer's Disease and Other Dementias, 34, 95-103. doi:10.1177/1533317518813555

Burns, A. (2000). The burden of Alzheimer's disease. The International Journal of Neuropsychopharmacology, 3, 31-38. doi:10.1017/S1461145700001905

Burton, E., Cavalheri, V., Adams, R., Browne, C. O., BoverySpencer, P., Fenton, A. M.,...Hill, K. D. (2015). Effectiveness of exercise programs to reduce falls in older people with dementia 
living in the community: A systematic review and meta-analysis. Clinical Interventions in Aging, 10, 421-434. doi:10.2147/CIA. S71691

Callahan, C. M., Boustani, M. A., Schmid, A. A., LaMantia, M. A., Austrom, M. G., Miller, D. K.,...Hendrie, H. C. (2017). Targeting functional decline in alzheimer disease: A randomized trial. Annals of Internal Medicine, 166, 164-171. doi:10.7326/ M16-0830

Caspersen, C. J., Powell, K. E., \& Christenson, G. M. (1985). Physical activity, exercise, and physical fitness: Definitions and distinctions for health-related research. Public Health Reports (Washington, DC: 1974), 100, 126-131.

Cohen, J. (1988). Statistical power analysis for the behavioral sciences (2nd ed.) Hillsdale: Erlbaum Associates.

D’Amico, F., Rehill, A., Knapp, M., Lowery, D., Cerga-Pashoja, A., Griffin, M.,...Warner, J. (2016). Cost-effectiveness of exercise as a therapy for behavioural and psychological symptoms of dementia within the EVIDEM-E randomised controlled trial. International Journal of Geriatric Psychiatry, 31, 656-665. doi:10.1002/gps.4376

Dawson, N., Judge, K. S., \& Gerhart, H. (2017). Improved functional performance in individuals with dementia after a moderate-intensity home-based exercise program: A randomized controlled trial. Journal of Geriatric Physical Therapy, 42(1), 18-27. doi:10.1519/JPT.0000000000000128

Ebly, E. M., Hogan, D. B., \& Rockwood, K. (1999). Living alone with dementia. Dementia and Geriatric Cognitive Disorders, 10, 541-548. doi:10.1159/000017202

Forbes, D., Thiessen, E. J., Blake, C. M., Forbes, S. C., \& Forbes, S. (2015). Exercise programs for people with dementia. The Cochrane Database of Systematic Reviews, (12), Cd006489. doi:10.1002/14651858.CD006489.pub3

Gonçalves, A. C., Cruz, J., Marques, A., Demain, S., \& Samuel, D. (2018). Evaluating physical activity in dementia: A systematic review of outcomes to inform the development of a core outcome set. Age and Ageing, 47, 34-41. doi:10.1093/ageing/afx135

Gonçalves, A. C., Samuel, D., Ramsay, M., Demain, S., \& Marques, A. (2019). A core outcome set to evaluate physical activity interventions for people living with dementia. Gerontologist, gnz100. doi:10.1093/geront/gnz100. [Epub ahead of print]

Heyn, P., Abreu, B. C., \& Ottenbacher, K. J. (2004). The effects of exercise training on elderly persons with cognitive impairment and dementia: A meta-analysis. Archives of Physical Medicine and Rehabilitation, 85, 1694-1704. doi:10.1016/j. apmr.2004.03.019

Holthoff, V. A., Marschner, K., Scharf, M., Steding, J., Meyer, S., Koch, R., \& Donix, M. (2015). Effects of physical activity training in patients with Alzheimer's dementia: Results of a pilot RCT study. PLoS One, 10, e0121478. doi:10.1371/journal. pone. 0121478

Lam, F. M., Huang, M. Z., Liao, L. R., Chung, R. C., Kwok, T. C., \& Pang, M. Y. (2018). Physical exercise improves strength, balance, mobility, and endurance in people with cognitive impairment and dementia: A systematic review. Journal of Physiotherapy, 64, 4-15. doi:10.1016/j.jphys.2017.12.001

Landis, J. R., \& Koch, G. G. (1977). The measurement of observer agreement for categorical data. Biometrics, 33(1), 159-174. doi: $10.2307 / 2529310$
Lewis, M., Peiris, C. L., \& Shields, N. (2017). Long-term home and community-based exercise programs improve function in community-dwelling older people with cognitive impairment: A systematic review. Journal of Physiotherapy, 63, 23-29. doi:10.1016/j.jphys.2016.11.005

Lowery, D., Cerga-Pashoja, A., Iliffe, S., Thuné-Boyle, I., Griffin, M., Lee, J.,...Warner, J. (2014). The effect of exercise on behavioural and psychological symptoms of dementia: The EVIDEM-E randomised controlled clinical trial. International Journal of Geriatric Psychiatry, 29, 819-827. doi:10.1002/gps.4062

McCurry, S. M., Pike, K. C., Vitiello, M. V., Logsdon, R. G., Larson, E. B., \& Teri, L. (2011). Increasing walking and bright light exposure to improve sleep in community-dwelling persons with Alzheimer's disease: Results of a randomized, controlled trial. Journal of the American Geriatrics Society, 59, 1393-1402. doi:10.1111/j.1532-5415.2011.03519.x

Moher, D., Liberati, A., Tetzlaff, J., \& Altman, D. G., PRISMA Group. (2009). Preferred reporting items for systematic reviews and meta-analyses: The PRISMA statement. PLOS Medicine, 6, e1000097. doi:10.1371/journal.pmed.1000097

Moïse, P., Schwarzinger, M., Um, M., \& Dementia Experts' Group. (2004). Dementia care in 9 OECD countries: A comparative analysis. Paris, France: OECD Publishing. doi:10.1787/485700737071

Öhman, H., Savikko, N., Strandberg, T. E., Kautiainen, H., Raivio, M. M., Laakkonen, M. L.,...Pitkälä, K. H. (2016). Effects of exercise on cognition: The Finnish Alzheimer disease exercise trial: A randomized, controlled trial. Journal of the American Geriatrics Society, 64, 731-738. doi:10.1111/jgs.14059

Öhman, H., Savikko, N. R. N., Strandberg, T. E., Kautiainen, H., Raivio, M. M., Laakkonen, M. L., . . Pitkälä, K. H. (2017). Effects of frequent and long-term exercise on neuropsychiatric symptoms in patients with Alzheimer's disease - Secondary analyses of a randomized, controlled trial (FINALEX). European Geriatric Medicine, 8(2), 153-157. doi:10.1016/j. eurger.2017.01.004

Padala, K. P., Padala, P. R., Lensing, S. Y., Dennis, R. A., Bopp, M. M., Roberson, P. K., \& Sullivan, D. H. (2017). Homebased exercise program improves balance and fear of falling in community-dwelling older adults with mild Alzheimer's disease: A pilot study. Journal of Alzheimer's Disease, 59, 565-574. doi:10.3233/JAD-170120

Physical Activity Guidelines Advisory Committee. (2018). 2018 Physical activity guidelines advisory committee scientific report. Washington, DC: U.S. Department of Health and Human Services. Retrieved from https://health.gov/paguidelines/secondedition/report/pdf/PAG_Advisory_Committee_Report.pdf

Pitkälä, K., Pöysti, M., Laakkonen, M., Tilvis, R., Savikko, N., Kautiainen, H., \& Strandberg, T. (2013). Effects of the Finnish Alzheimer disease exercise trial (FINALEX): A randomized controlled trial. JAMA Internal Medicine, 173(10), 894-901. doi:10.1001/jamainternmed.2013.359

Pitkälä, K., Savikko, N., Poysti, M., Strandberg, T., \& Laakkonen, M. L. (2013). Efficacy of physical exercise intervention on mobility and physical functioning in older people with dementia: A systematic review. Experimental Gerontology, 48, 85-93. doi:10.1016/j.exger.2012.08.008

Potter, R., Ellard, D., Rees, K., \& Thorogood, M. (2011). A systematic review of the effects of physical activity on physical 
functioning, quality of life and depression in older people with dementia. International Journal of Geriatric Psychiatry, 26, 1000-1011. doi:10.1002/gps.2641

Prick, A. E., de Lange, J., Scherder, E., Twisk, J., \& Pot, A. M. (2017). The effects of a multicomponent dyadic intervention with physical exercise on the cognitive functioning of people with dementia: A randomized controlled trial. Journal of Aging and Physical Activity, 25, 539-552. doi:10.1123/ japa.2016-0038

Prince, M., Wimo, A., Guerchet, M., Ali, G., Wu, Y., \& Prina, M. (2015). World Alzheimer report 2015: The global impact of dementia.London, UK: Alzheimer's Disease International. Retrieved from https://www.alz.co.uk/research/world-report-2015

Rao, A. K., Chou, A., Bursley, B., Smulofsky, J., \& Jezequel, J. (2014). Systematic review of the effects of exercise on activities of daily living in people with Alzheimer's disease. The American journal of Occupational Therapy, 68, 50-56. doi:10.5014/ ajot.2014.009035

Regier, N. G., Hodgson, N. A., \& Gitlin, L. N. (2016). Characteristics of activities for persons with dementia at the mild, moderate, and severe stages. Gerontologist, 57(5), 987-997. doi:10.1093/ geront/gnw133

Sallis, J. F., Bull, F., Guthold, R., Heath, G. W., Inoue, S., Kelly, P., . . ., Hallal, P. C. (2016). Progress in physical activity over the Olympic quadrennium. Lancet, 388(10051), 1325-1336. doi:10.1016/S0140-6736(16)30581-5

Steinberg, M., M., L. J., Podewils, L. J., \& Lyketsos, C. G. (2009). Evaluation of a home-based exercise program in the treatment of Alzheimer's disease: The Maximizing Independence in Dementia (MIND) study. International Journal of Geriatric Psychiatry, 24(7), 680-685. doi:10.1002/gps.2175

Suttanon, P., Hill, K. D., Said, C. M., Byrne, K. N., \& Dodd, K. J. (2012). Factors influencing commencement and adherence to a home-based balance exercise program for reducing risk of falls: Perceptions of people with Alzheimer's disease and their caregivers. International Psychogeriatrics, 24, 1172-1182. doi:10.1017/S1041610211002729

Suttanon, P., Hill, K. D., Said, C. M., Williams, S. B., Byrne, K. N., LoGiudice, D.,...Dodd, K. J. (2013). Feasibility, safety and preliminary evidence of the effectiveness of a home-based exercise programme for older people with Alzheimer's disease: A pilot randomized controlled trial. Clinical Rehabilitation, 27, 427438. doi:10.1177/0269215512460877
Teri, L., Gibbons, L. E., McCurry, S. M., Logsdon, R. G., Buchner, D. M., Barlow, W. E.,...Larson, E. B. (2003). Exercise plus behavioral management in patients with Alzheimer disease: A randomized controlled trial. JAMA, 290, 2015-2022. doi:10.1001/jama.290.15.2015

Van Ooteghem, K., Musselman, K., Gold, D., Marcil, M. N., Keren, R., Tartaglia, M. C., . . I Iaboni, A. (2018). Evaluating mobility in advanced dementia: A scoping review and feasibility analysis. Gerontologist, 59, e683-e696. doi:10.1093/geront/ gny068

Venturelli, M., Scarsini, R., \& Schena, F. (2011). Six-month walking program changes cognitive and ADL performance in patients with Alzheimer. American Journal of Alzheimer's Disease and Other Dementias, 26, 381-388. doi:10.1177/1533317511418956

Verhagen, A. P., de Vet, H. C., de Bie, R. A., Kessels, A. G., Boers, M., Bouter, L. M., \& Knipschild, P. G. (1998). The Delphi list: A criteria list for quality assessment of randomized clinical trials for conducting systematic reviews developed by Delphi consensus. Journal of Clinical Epidemiology, 51, 1235-1241. doi:10.1016/s0895-4356(98)00131-0

Vreugdenhil, A., Cannell, J., Davies, A., \& Razay, G. (2012). A community-based exercise programme to improve functional ability in people with Alzheimer's disease: A randomized controlled trial. Scandinavian Journal of Caring Sciences, 26, 12-19. doi:10.1111/j.1471-6712.2011.00895.x

van der Wardt, V., Hancox, J., Gondek, D., Logan, P., Nair, R. D., Pollock, K., \& Harwood, R. (2017). Adherence support strategies for exercise interventions in people with mild cognitive impairment and dementia: A systematic review. Preventive Medicine Reports, 7, 38-45. doi:10.1016/j.pmedr.2017.05.007

Wesson, J., Clemson, L., Brodaty, H., Lord, S., Taylor, M., Gitlin, L., \& Close, J. (2013). A feasibility study and pilot randomised trial of a tailored prevention program to reduce falls in older people with mild dementia. BMC Geriatrics, 13, 89. doi:10.1186/1471-2318-13-89

World Health Organization. (2012). Dementia: A public health priority. Geneva, Switzerland: Author. Retrieved from https://apps. who.int/iris/bitstream/handle/10665/75263/9789241564458_ eng.pdf

Zeng, Z., Deng, Y., Shuai, T., Zhang, H., Wang, Y., \& Song, G. (2016). Effect of physical activity training on dementia patients: A systematic review with a meta-analysis. Chinese Nursing Research, 3(4), 168-175. doi:10.1016/j.cnre.2016.11.006 